\title{
A maestria de Pierre Monbeig
}

[ The mastery of Pierre Monbeig

\author{
Eduardo Dutenkefer ${ }^{\mathrm{I}}$
}

Fernanda Padovesi Fonseca ${ }^{2}$

Jaime Tadeu Oliva ${ }^{3}$

DUTENKEFER, Eduardo; FONSECA, Fernanda Padovesi; OLIVA, Jaime Tadeu. A maestria de Monbeig. Revista do Instituto de Estudos Brasileiros, Brasil, n. 64, p. 344-35I, ago. 2016.

DOI: http://dx.doi.org/Io.II606/issn.23I6-90IX.voi64p344-35I

I Universidade de São Paulo (USP, São Paulo, SP, Brasil).

2 Universidade de São Paulo (USP, São Paulo, SP, Brasil).

3 Universidade de São Paulo (USP, São Paulo, SP, Brasil). 
No acervo documental de Pierre Monbeig4 sob a guarda do IEB55, há vários mapas originais desenhados a "bico de pena" pelo geógrafo francês. Trata-se de um conjunto precioso para os pesquisadores. São mapas que, mais do que mostrar uma maestria comum aos geógrafos da época, revelam que Monbeig não prescindia da prática cartográfica como meio de visualização e reflexão dos fenômenos que estudava. Dois desses mapas exemplificam bem a importância da cartografia em seus trabalhos.

4 (Marissel, França, I908 - Paris, França, I987). Geógrafo e professor, formou-se em Paris em I93I. Chegou ao Brasil em I935, contratado pela então recém-criada Faculdade de Filosofia, Ciências e Letras da USP para assumir a cátedra de Geografia Humana, substituindo o professor Pierre Deffontaines. Em sua permanência na USP (I935-I946), orientou toda uma geração que se iniciava nos estudos geográficos, estimulando em especial a investigação sobre cidades e áreas de colonização. Com outros professores, criou a Associação dos Geógrafos Brasileiros (I945). Retornou à França em I946, onde lecionou em várias instituições, entre elas a Sorbonne. Foi agraciado com vários prêmios e títulos como o da Fundação Nacional de Ciências Políticas de Paris e o Auguste Logerot da Sociedade de Geografia da França. Na sua produção bibliográfica destacam-se Pioneiros e fazendeiros de São Paulo, La croissance de la ville de San Paulo, Ensaios de geografia humana brasileira e Novos estudos de geografia humana brasileira . In: 〈http://www.ieb.usp.br/guia-ieb/detalhe/I6I〉. Acesso em: I9 jul. 2016. 5 Acervo comprado pelo Banco Sudameris da viúva de Pierre Monbeig, Julieta Monbeig, e posteriormente doado à Universidade de São Paulo onde foi incorporado ao acervo do Instituto de Estudos Brasileiros - IEB/ USP, em I990. Em I995 ele foi incrementado por doação feita pelos seus filhos. Algumas informações sobre o acervo: No Arquivo: Sigla: BR USP/IEB PM. Cadernos e cadernetas com anotações realizadas durante estudos de campo, fotografias, cadernos de viagem. Há também registros de levantamentos bibliográficos, anotações para trabalho, recortes de jornais com artigos do titular e de terceiros, manuscritos de obras publicadas, plantas e cartas geográficas (mapas), dados estatísticos sobre produtos agrícolas. Quantidade: 2.200 documentos. Estado de organização: totalmente processado. Na Biblioteca: Sigla: PM. Livros e revistas sobre o Brasil e a América Latina, principalmente nas áreas de geografia, economia, política. Quantidade: Aproximadamente I.200 volumes. Estado de organização: Parcialmente processado. In: 〈http://www.ieb.usp.br/guia-ieb/detalhe/I6I〉. Acesso em: I9 jul. 20I6. Arquivo organizado pela professora Heliana Angotti-Salgueiro. Para obter outras informações sobre esse trabalho, ver: ANGOTTI-SALGUEIRO, Heliana. Arquivo Pierre Monbeig: uma experiência integrada de dados textuais e iconográficos inscritos na vida do titular. In: CONGRESSO INTERNACIONAL DE ARQUIVOS, BIBLIOTECAS, CENTROS DE DOCUMENTAÇÃO E MUSEUS, I. 2002, São Paulo. Integrar, Atas... São Paulo: Imprensa Oficial, 2002, p. 5II-527. 
Eles foram preparados para a sua Tese complementar de doutorado de I949 (figura I) sobre o crescimento da cidade de São Paulo.

\section{IA CROISSANCE DE LA VILLE DE SAO PAULO (Brés1l)}

\section{Thèse Complémentaire pour le Doctorat ès-Lettres prósentée \\ par}

\section{Plerre W $O$ II B E I G \\ Ancien Professeur à l'Université de Sêo Paulo \\ Chargé d'Enselgnement à la Faculté des Lettres de l'Université de Strasbourg.}

Figura I - Fac-símile da capa do doutorado complementar de Pierre Monbeig. Arquivo IEB

Os dois mapas (figuras 2 e 3) representam a densidade demográfica de São Paulo em I940 e I947, respectivamente. Posteriormente, eles foram publicados em I953 na Revue de géographie alpine no artigo "La croissance de la ville de Sao Paulo".

6 O artigo encontra-se no tomo 4I n. I e 2. Disponível em:<http://www.persee.fr/doc/rga_O035-II2I_I953_ num_4I_I_I083>. Acesso em: I9 jul. 20I6. Foi também publicado em português, mas os mapas não aparecem na tradução: MONBEIG, Pierre. O crescimento da cidade de São Paulo. In: SZMRECSÁNYI, Tamás (Org.). História econômica da cidade de São Paulo. São Paulo: Globo, 2004, p. I4-II5. 


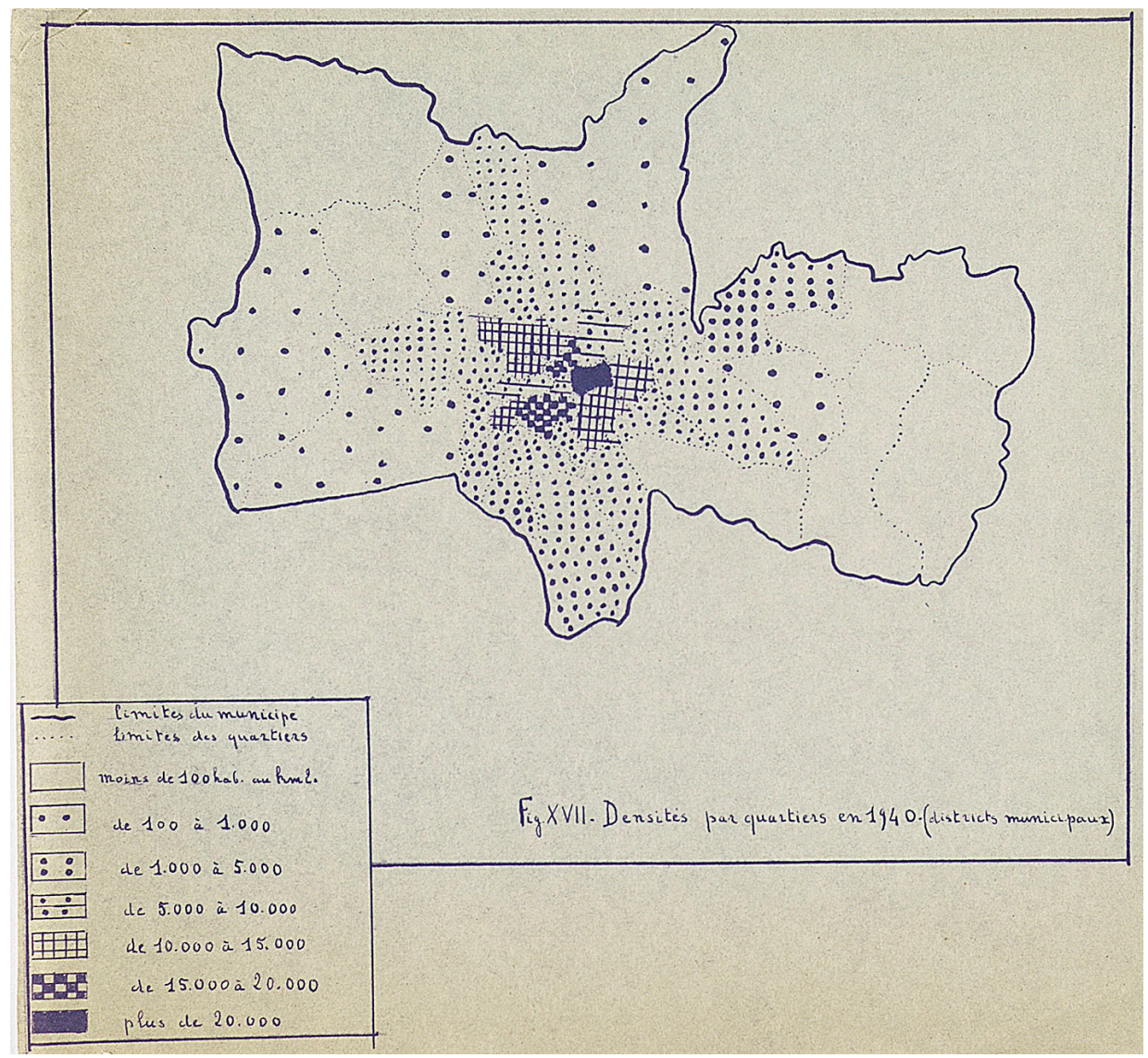

Figura 2 - Mapa de densidade populacional de São Paulo em I940 


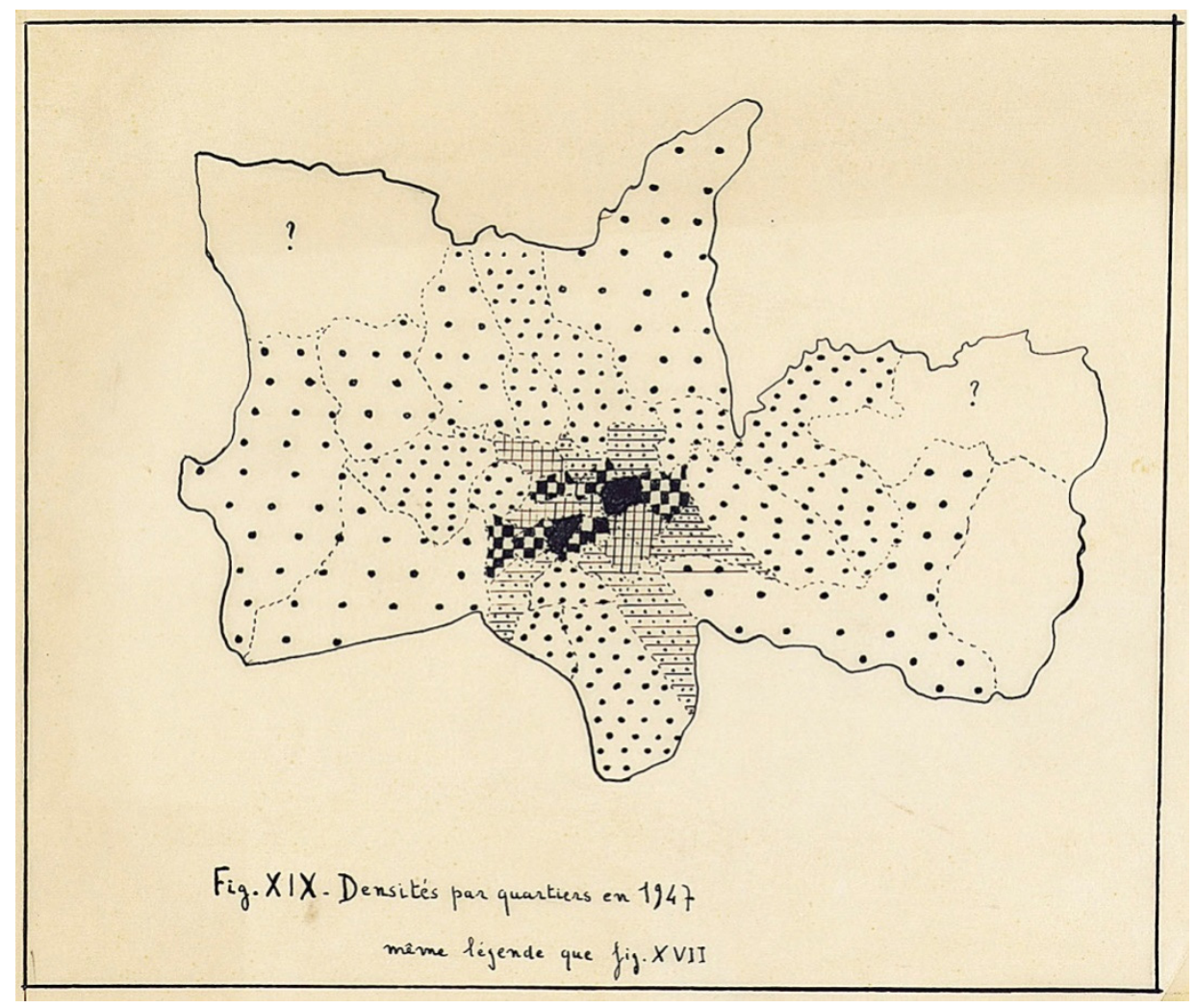

Figura 3 - Mapa de densidade populacional de São Paulo em I947

A aparência simples e despretensiosa, reforçada pela confecção manual, pode enganar e levar a crer que se trata de uma "cartografia rústica" em virtude das técnicas e dos recursos contemporâneos empregados na produção de mapas. Nada mais enganoso. Trata-se de um mapa sofisticado do ponto de vista de linguagem. Monbeig fazia parte de uma tradição da escola francesa ${ }^{7}$ muito preocupada com a expressão visual dos fenômenos, naturais e sociais, e muito ciosa de uma linguagem padronizada e estável, que não gerasse dúvidas no observador.

Nos mapas, Pierre Monbeig representa as densidades demográficas na cidade de São Paulo fazendo uso da variável visual valor, como seria designado atualmente após a sistematização das variáveis visuais proposta por Jacques Bertin. Era uma forma

7 Em I934 foi fundada a Ecole de cartographie de l'Université de Paris por Emmanuel de Martonne. O objetivo da escola era formar “cartógrafos que fossem também geógrafos”. Foi nessa escola que se formou Jacques Bertin, que nos anos I960 lançou uma obra referencial na área: Semiologie graphique: les diagrammes, les reseaux, les cartes. PALSKY, Gilles et ROBIC, Marie-Claire. Aux sources de la sémiologie graphique. Cybergeo: European Journal of Geography. Dossiers. I997 - Colloque “30 ans de sémiologie graphique”, document I47, mis en ligne le I7 novembre 2000. Disponível em: 〈http://cybergeo.revues.org/554〉. Acesso em: 4 ago. 20I6. DOI: IO.4000/ cybergeo. 554 
comum para representar fenômenos ordenados numa época em que predominavam mapas impressos em preto e branco ${ }^{8}$. Alguns aspectos que vale sublinhar:

- nos dois mapas ele ordenou visualmente as diferentes densidades a partir do branco para o preto com um modo de implantação zonal';

- a maior presença do branco situa-se onde as densidades são menores (o branco total refere-se a menos de Ioo hab. $/ \mathrm{km}^{2}$ ) e, à medida que as densidades crescem, aumenta a presença do preto por meio de pontos e tramas que vão se intensificando até chegar ao preto total na máxima densidade demográfica da cidade, que é a de $20.000 \mathrm{hab} . / \mathrm{km}^{2}$;

- há nos mapas uma lógica comum presente na relação existente entre os objetos representados (no caso, diferentes densidades demográficas) e na relação entre os elementos escolhidos para representar essas densidades explicitados na legenda. Quanto menor a densidade, menor a presença de preto, e o contrário também é verdadeiro. Caso não fosse feito assim, ele teria produzido o que Jacques Bertin denomina como falsa imagem.

- como ambos os mapas mantêm a mesma linguagem e as mesmas classes de níveis de densidade demográfica, isso os torna comparáveis. O que parece trivial no caso costuma ser raro na produção cartográfica, pois há uma instabilidade notória no que diz respeito às linguagens e aos métodos empregados (por vezes por parte de um mesmo autor), o que faz da comparação entre mapas um exercício árduo. Jacques Bertin advertia que mapas que têm a qualidade de serem facilmente comparáveis em termos visuais são uma necessidade primordial de uma cartografia moderna ${ }^{\mathrm{T}}$.

Por fim, dois breves comentários informativos sobre o conteúdo dos mapas: I) provavelmente Pierre Monbeig utiliza a divisão distrital (distritos de paz) de I940 ${ }^{\text {II }}$, que totalizava 40 distritos. Ele deixa de fora os distritos de Ibirapuera, Santo Amaro e Capela do Socorro, que juntos formavam o antigo município de Santo Amaro, integrados ao município de São Paulo em I935 (ver figura 4); 2) com uma rápida visualização (mapas são para ver e não para ler), percebe-se os distritos que tiveram maior aumento nas suas densidades entre I940 e I947. As maiores densidades estão no centro e em suas cercanias, e os eixos que conhecem o maior incremento em suas densidades são os que se posicionam a sudoeste, principalmente, e a sudeste.

8 Exemplos dessa cartografia da época podem ser encontrados em: ROBIC, Marie-Claire. Une école pour des universitaires placés aux marges de l'expertise: les années trente et la cartographie géographique. Cybergeo: European Journal of Geography. Dossiers, Colloque “30 ans de sémiologie graphique”, document I55, mis en ligne le I7 novembre 2000. Disponível em: 〈http://cybergeo.revues.org/I643〉. Acesso em: 4 ago. 20I6. DOI: I0.4000/cybergeo.I643

9 Implantação zonal é quando se mapeia a extensão e não uma localização isolada, por exemplo. No caso dos mapas, o que está mapeado é a extensão de cada distrito municipal da cidade de São Paulo.

Io Cf. BERTIN, Jacques. Ver ou ler. Seleção de Textos (AGB), São Paulo, n. I8, p. 45-62, maio I988.

II Segundo o decreto-lei municipal n ${ }^{\circ} 25$ de 30/03/I940. SÃO PAULO. Departamento de Estatística. Linhas divisórias do município de São Paulo. São Paulo: setembro de I942. 99 p. Disponível em: <http://produtos.seade.gov. br/produtos/bibliotecadigital/view/singlepage/index.php?pubcod=I00I3033\&parte=I $>$. Acesso em: I set. 2014 . 


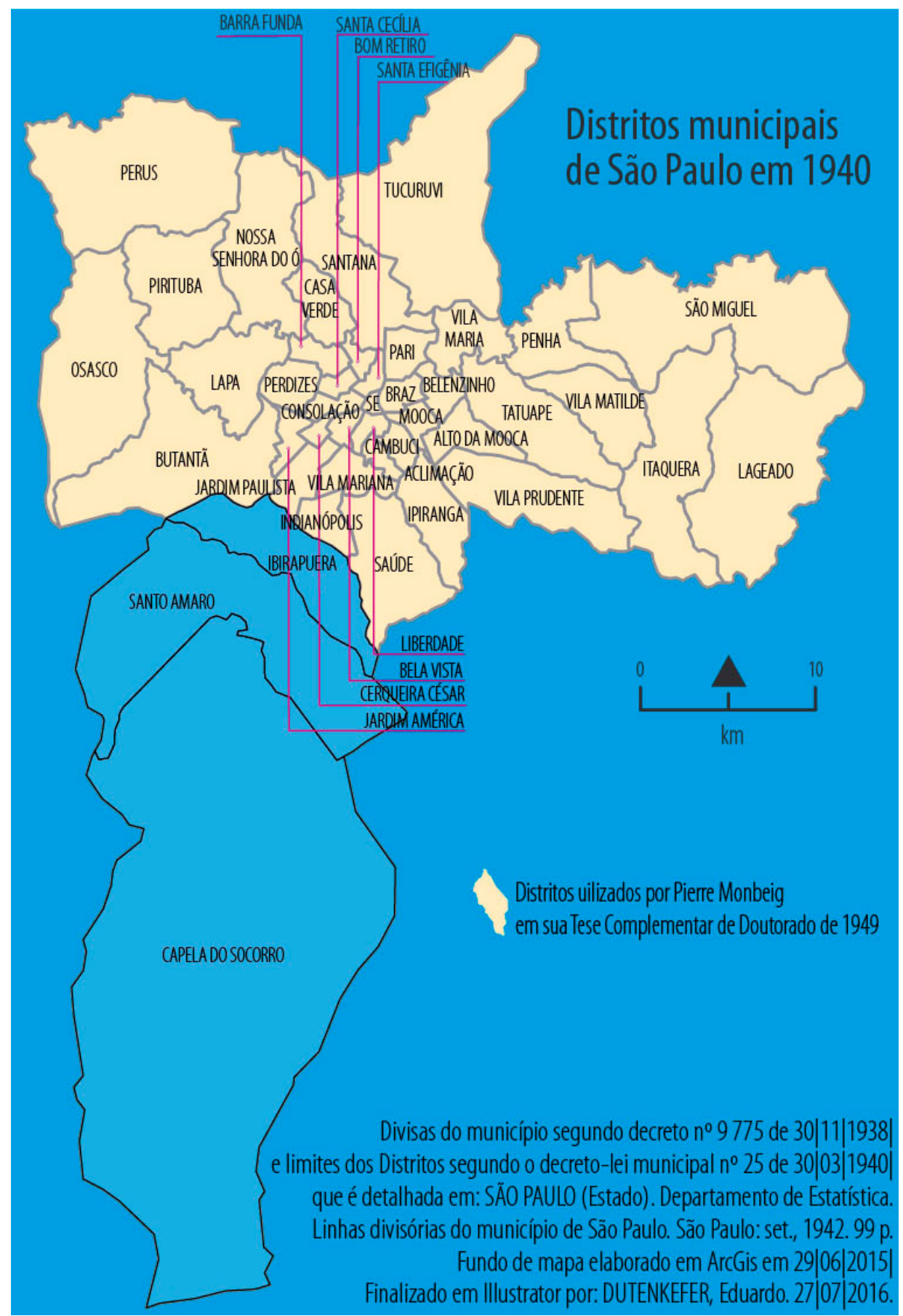

Figura 4-Distritos municipais de I940 


\section{SOBRE OS AUTORES}

EDUARDO DUTENKEFER é mestre em Geografia e doutorando no Programa de Pós-graduação em Geografia Humana da FFLCH/USP, Brasil.

E-mail: dutenkefer@gmail.com

FERNANDA PADOVESI FONSECA é professora de Cartografia no Departamento de Geografia da Faculdade de Filosofia, Letras e Ciências Humanas da Universidade de São Paulo (FFLCH/USP).

E-mail: ferpado@gmail.com

JAIME TADEU OLIVA é professor e pesquisador da área de geografia do Instituto de Estudos Brasileiros IEB/USP.

E-mail: jtoliva@gmail.com; jtoliva@usp.br

\section{REFERÊNCIAS BIBLIOGRÁFICAS}

ANGOTTI-SALGUEIRO, Heliana. Arquivo Pierre Monbeig: uma experiência integrada de dados textuais e iconográficos inscritos na vida do titular. In: CONGRESSO INTERNACIONAL DE ARQUIVOS, BIBLIOTECAS, CENTROS DE DOCUMENTAÇÃO E MUSEUS, I. 2002, São Paulo. Integrar, Atas... São Paulo: Imprensa Oficial, 2002, p. 5 II-527.

BERTIN, Jacques. Ver ou ler. Seleção de Textos (AGB), São Paulo, n. I8, maio I988, p. 45-62.

MONBEIG, Pierre. O crescimento da cidade de São Paulo. In: SZMRECSÁNYI, Tamás (Org). História econômica da cidade de São Paulo. São Paulo: Globo, 2004, p. I4-II5.

PALSKY, Gilles et ROBIC, Marie-Claire. Aux sources de la sémiologie graphique. Cybergeo: European Journal of Geography. Dossiers. I997 - Colloque “30 ans de sémiologie graphique”, document I47, mis en ligne le I7 novembre 2000. Disponível em: 〈http://cybergeo.revues.org/554〉. Acesso em: 4 ago. 20I6. DOI: I0.4000/cybergeo.554

ROBIC, Marie-Claire. Une école pour des universitaires placés aux marges de l'expertise: les années trente et la cartographie géographique. Cybergeo: European Journal of Geography. Dossiers, Colloque " 30 ans de sémiologie graphique”, document I55, mis en ligne le I7 novembre 2000. Disponível em: 〈http:// cybergeo.revues.org/I643>. Acesso em: 4 ago. 20I6. DOI: 10.4000/cybergeo.I643

SÃO PAULO. Departamento de Estatística. Linhas divisórias do município de São Paulo. São Paulo: setembro de I942, 99 p. Disponível em: <http://produtos.seade.gov.br/produtos/bibliotecadigital/view/singlepage/index.php?pubcod=Ioor3033\&parte=I $>$. Acesso em: I set. 2014 . 